\title{
Insurance culture in russia and financial literacy as measures to reduce economic risks on state and personal levels
}

\author{
Olga Medyanik ${ }^{*}$, Dr. Sergey A. Belozyorov ${ }^{2}$ and Stanislav Medyanik ${ }^{3}$ \\ ${ }^{1}$ Assistant of Department of Political Psychology, St. Petersburg state University, 199034, \\ Nab. Makarova, H. 6, Saint-Petersburg, Russia,
}

${ }^{2}$ Professor Head of the Department, Dept. of Risk Management and Insurance Chief Researcher, Laboratory of Asian Economic Studies, Vice Dean for Academic Affairs Department of Risk Management and Insurance, St. Petersburg state University, 191123, St. Petersburg, Tchaikovsky street, 62

${ }^{3}$ Bachelor of Department of Political Psychology, St. Petersburg state University, 199034, Nab. Makarova, H. 6, Saint-Petersburg, Russia,

\begin{abstract}
In nowadays conditions, insurance provides the opportunity for market system of economic management to work in any state. To provide economic security of the person it is needed to create a mechanism of protection against internal and external threats in modern Russia. That's why the role of citizens insurance policy is increasing as the most effective risk management institute and achieving safety of health and private property of citizens. The goal of this research is to study Russian citizens' attitudes towards insurance policy and investment using the conception of personal economic security. The preparatory study stage was focused on theoretical understanding of economic security problems taking insurance field as an example. Empirical research consisted of four stages (2008-2019). There were 1793 people taking part in this research. The article presents the results of the last 4 stage of empirical research. Results of this study can be proposed in the program of improving the functioning of the insurance market in the Russian Federation in The framework of the strategy of development of the insurance market - 2020. The obtained results can be used in Politics and Economics in the development of a set of measures related to lawmaking, control of financial institutions, promotion of financial literacy of the population, preparation of courses for universities and trainings for participants of the insurance market.
\end{abstract}

Keywords: insurance behaviour, the typology of the policyholders, economic security of the individual, financial literacy in the insurance industry, insurance culture. 


\section{Introduction}

Insurance culture in modern Russia is a relatively new phenomenon and is in constant development. The insurance behaviour of a Russian citizen does not have rigid rationalistic features and differs, for example, from the Western European one by its desire to receive benefits as a result of a "lucky event", calculation "at random" [1].

In Russia, due to the socio-historical features of development, economic behaviour is often irrational. Such a distinctive feature of the Russian man brings moments of uncertainty in the situation associated with economic choice. State policy of insurance, of course, should take into account a special mental approach in the economic behaviour of the Russian citizen in the promotion of reforms and laws. Perhaps the Appendix of the experience of Japan, China and other countries, where the success of socio-economic reforms was achieved by combining the achievements of the modern market mechanism with national traditions, is productive in the Russian conditions.

Insurance culture in modern Russia has become another vital element in the system of skills and rules of economic behaviour. It is inextricably linked with the financial planning of the citizen. Financial planning - is that part of the economic behaviour of the citizen, which in Russia is just beginning to emerge as a financial strategy. Presumably, financial planning reduces the fear of uncertainty, reduces the risk behaviour of the economic actor and increases the economic security of the individual and confidence in financial institutions.

It is assumed that financial planning reduces the fear of uncertainty, reduces the risk behaviour of the economic actor and increases the economic security of the individual and confidence in financial institutions. Financial literacy allows a person not to depend on circumstances, on the will of other people, the system. A financially educated person independently chooses the paths in life that will be for him the most attractive, creating a material basis for the further development of not only themselves but also society as a whole. In a number of countries, for example Great Britain, USA, Germany [2] programs and projects to improve financial literacy are designed to promote a voluntary national philosophy of "self-reliance", so that every citizen can achieve financial independence and maintain it in old age. A good level of financial literacy is necessary for everyone not only to achieve their personal financial goals, but also to ensure the life cycle. Whatever the specific goal, the benefits of financial literacy will be improved living standards, confidence in the future, stability and prosperity of the economy as a whole.

Historically, financial planning has not been based on strict academic knowledge and remains under-reported by many universities, as evidenced by the scarcity of special courses and research programs (Gupta, 2011). The professionalization of this area requires basic professional knowledge, which should go beyond purely professional knowledge and skills development. While there is some scientific debate that financial planning is a professional knowledge base that should aim to foster rationalistic traits in the character of the individual and should be amenable to systematic development (Gupta, 2011). 
In 2013, the G20 leaders called on the OECD/IFRS to develop a concept of basic knowledge and skills on financial literacy for both youth and adults. Today, many countries, including Russia, are implementing large-scale educational programs on financial literacy. They focus on a number of core knowledge and skills that are or are likely to become relevant in countries and target groups, making it a valuable tool for policy implementation, regardless of national factors such as the level of economic development or the existence of a national financial education strategy [4]. But as the practice of conducting courses on financial literacy, for example, teacher training programs in the framework of the project to improve the financial literacy of students of Russian Universities (November-December 2018), the programs and the textbook on financial literacy do not take into account the Russian specifics and require further development in theoretical and applied material.

In the study of the C.D. Reef and B.N. Singler, it is shown that the planning of the goal is associated in the individual with a great sense of self-control, which in turn increases the sense of well-being [Ryff\&Singler, 2008]. Planning reflects a desire to anticipate or control life. Riff and Singler used the term "high-performance environment" to refer to an individual's ability to organize and create an environment that meets their needs and capabilities. An individual living in a highly efficient environment skilfully manages his economic problems and everyday Affairs, controls the complex of external activity events and makes effective use of the surrounding reality [Ryff\&Singler, 2008]. A sense of control over life or masterful planning of one's life provides mental health, including reducing anxiety and depression, and increases life satisfaction and gives feelings of happiness and well-being. Thus, planning for the future facilitates a sense of control and anxiety, which in turn increases satisfaction with their lives and society as a whole. Insurance, as a system of annual extension of contracts, of course, creates a certain form of financial planning of citizens, reduces uncertain the stability of the financial situation.

The source of danger may be individual psychological characteristics of the individual, affecting the adequacy of its important economic decisions. Internal sources of threats to the economic security of the individual are inherent in the very biosocial nature of the human psyche, in the peculiarities of its formation and functioning, in the individual-personal characteristics of the individual. Due to these features of the individual differ in the degree of perception of various influences, the ability to analyze and evaluate economic information coming from the outside. The decision of the subject to invest personal money in a particular investment (and insurance) product forms the driving force of the economy. However, the fact that these decisions can be irreversible because of the uncertainty of the consequences of investments and the riskiness of transactions can bring certain experiences to the individual. After all, private investors can only manage the risk they take. This is not the end of the problem. People are getting older, wiser, richer or poorer, and the understanding of risk and the degree of risk aversion is changing in one way or another.

In 1990, Nobel laureate W.F. Sharpe published an article in which he analyzed the ratio of wealth and the desire of investors to invest in risky transactions. He hypothesized that changes in wealth affect the degree of risk aversion. The growth of wealth increases the ability of people to endure losses, but losses reduce this ability. 
As a consequence, increasing wealth coupled with a greater "risk appetite" [Overton, 2008].

Thus, insurance culture and financial literacy form the basis for the sense of security of the individual in the economy. If we talk about the development of such financial institutions of savings and insurance in Russia, the process of saving has its own specifics, partly socially-psychological, not economic. First, the share of funds allocated for accumulation is relatively small, since there is no habit to make savings in modern forms due to the market type of economy (insurance, purchase of securities) and the average income is relatively small. Secondly, savings are mainly aimed at short-term consumption (travel, car purchase). Thirdly, the unstable social and economic situation in the country acts as a deterrent to the accumulation of funds and their transformation into investment. Only if the achievement of relative stability, people may receive an incentive to insurance of property and other risks, the accumulation of savings and their transformation into investment.

Based on the analysis of existing models of well-being, we have proposed a theoretical the structure of concepts of insurance behaviour of the citizen in the modern market economy, where the basis of the "internal state" of financial wellbeing is the economic security of the individual, which is a factor of insurance behaviour (Tab.1):

Table 1: The structure of concepts of insurance behaviour

\begin{tabular}{|c|c|}
\hline Concepts & Authors \\
\hline $\begin{array}{l}\text { economic security of the person and } \\
\text { financial }\end{array}$ & $\begin{array}{l}\text { O.S. Deyneka,O. V. Kurysheva, I. A. Baeva, R. Rea } \\
\text { E. Deci }\end{array}$ \\
\hline insurance culture and economic trust & $\begin{array}{l}\text { V.M.Minina, A. L. Zhuravlev, V. P. Poznyakov, S. I } \\
\text { Gurieva, L. P. Pochebut, T. A. Nestik }\end{array}$ \\
\hline financial literacy, financial planning & $\begin{array}{l}\text { S. A. Belozerov, G. V. Chernova, A. N. Bazanov, B. } \\
\text { Gupta, C.D. Ryff, B.N. Singler }\end{array}$ \\
\hline $\begin{array}{l}\text { economic attitudes, economic values, } \\
\text { economic beliefs in the context of insurance } \\
\text { socialization of citizens }\end{array}$ & E. Kirhler, K.Gangl, W.Sharp, J. Akerlov, R. Shiller \\
\hline $\begin{array}{l}\text { fear of loss of life, health and property, } \\
\text { financial anxiety, financial concerns }\end{array}$ & $\begin{array}{l}\text { Eileen Y. Chou, BidnanL. Parmar, Adam D. Galinsky, } \\
\text { Mailis-Gagnon A., B. Yegneswaran, K Nicholson, S. } \\
\text { Lakha,M. Papagapiou, A. Steiman, M. Zurowski. }\end{array}$ \\
\hline
\end{tabular}

At the first level of the structure are the incentives, motivations and needs of insurance behaviour, which encourages the citizen to the active search and analysis of insurance products and partners the insurance market. At the second level, insurance market agents (insurance agents, brokers, representatives of insurance companies, banks) and state insurance policy (a collective concept that includes legislative reforms in the insurance sector, informing the population in economic policy, monitoring and supervising the activities of non-state insurance companies) form the beliefs and attitudes of the insured and ensure the processes of insurance socialization. The third level is poorly represented in the Russian insurance policy and in our structure, it has advisory nature. Without it, there is no full and conscious transition of 
policyholders to the fourth and fifth stage, which demonstrate the effectiveness of the insurance Institute.

Thus, insurance culture and financial literacy form the basis for the sense of security of the individual in the economy. If we talk about the development of such financial institutions as savings and insurance in Russia, saving process has its own specifics, partly socio-psychological, not economic. First, the share of funds allocated to accumulation is relatively small, since the habit of making savings in modern forms, conditioned by the market type of economy (insurance, purchase of security) and the average income is relatively small. Secondly, savings are mainly aimed at short-term consumption, for example, travelling, buying a car. Thirdly, the unstable socio-economic situation in the country acts as a deterrent to the accumulation of funds and their transformation into investments. Only if we achieve stability, people may receive an incentive to insurance of property and other risks, the insurance trust to the agents of the insurance market policy made by the government.

The methodological basis of the study was an interdisciplinary approach, traditional for political and economic psychology, involving the synthesis of psychological, economic, political science and sociological knowledge. The study was based on methodological principles and approaches systematized by O.S. Deyneka [Deyneka, 2015]. Of all the approaches considered by her during studying political and economic consciousness (systemic, leveled, typological, resource, situational, etc.), special attention was paid to the typological approach.

The typological approach as a variant of the personal approach is justified against the background of increasing uncertainty in the economic and political spheres of life, the progressive diversity of goods, services, information and communications. In a generalized, modeling form, it introduces the "human factor" into political life and economic activity (taking into account the geopolitical, cultural, historical and psychological factors of mentality), facilitates a holistic description of how political and economic activity proceeds and how political actors and economic entities" [Deyneka, 2015].

The research methodology also took into account the following concepts:

- the factor of personal satisfaction with the policy of insurance and investment in Russia;

- the factor of satisfaction with quality of life and confidence in the future;

-the factor of personal satisfaction with the state of own economic security in the process of investment and insurance.

The following psychological characteristics and criteria were incorporated into the concept of modeling insurance behavior:

- the motive of insurance behavior (internal motivation caused by a combination of external and internal reasons for citizen participation in the insurance activity). External causes have the circumstances (risks) capable of causing property or other material damage, the occurrence of which cannot be prevented, natural phenomena (flood, hurricane), circumstances caused by the activity of the person himself (accident), random events that constantly accompany the person (injury), etc. Internal causes, mainly rely on the psychological factor. This is the appearance of people's fears for the safety and saving of material and personal non-material benefits and the 
need, as well as the desire to fight with accessible methods against the dangers that cause their fear of harmful consequences;

- psychological relations, preferences and consumer confidence in insurance policy. The motives are followed by certain preferences and attitudes, and even before the policyholder understands what he really needs and consumer confidence, when a person begins to realize their needs in insurance. A citizen still needs a strong enough motivation based on trust, so he began to act in the market in search of a way to meet their insurance preferences;

- experience of economic security in insurance policy (fear and insurance in the context of economic behavior of the individual an indicator of adaptive behavior in front of internal and external threats, the way a person responds to changes in his social and economic life). The phenomenon of fear in the context of insurance institutions in the economy plays the role of social mobilization, prevention of risk negative events, planning of financial behavior of a person and his family. This is the sensory perception of a person, a kind of prerequisite for the perception or awareness of people's needs.

\section{Materials and Methods}

We developed an inventory to measure citizens' perception of insurance policy (PIP), which was created on the basis of previous inventories [Medyanik O., 2017], the materials of theoretical analysis and longitudinal study [Medyanik O., 2018] and is intended for practical use.

According to the analysis of theoretical concepts and empirical researches themselves the inventory of PIP included five main directions:

- expediency of insurance (benefit). Citizen's perception of insurance policy (PIP) is based on the assessment of the feasibility and necessity of purchasing insurance products. The assessment of expediency is determined by the list of assumed risks, taking into account the probability of their occurrence and the awareness of losses that can occur under adverse circumstances;

- rationality of choice (price, availability, service). Rationality largely depends on the marketing preferences of the consumer, which is determined by the benefits of purchasing an insurance policy, economic patriotism, financial literacy (education) of the citizen;

- risk susceptibility (acceptance, transfer, risk avoidance). This indicator is determined by the individual aspect of the citizen's susceptibility to risk especially who the citizen is ready to transfer on responsibility for the preservation of his property in case of danger: the state, insurance companies, relatives and friends or himself;

- financial anxiety (internal feeling of economic security, financial uncertainty). Characteristics of financial anxiety become a component of general subjective citizens' perception of insurance. The PIP Inventory also reflects the positivity and negativity of the individual's thoughts and expectations about his financial future, taking into account the manifestation of anxiety and anxiety for his stability and the experience of satisfying consumption in the insurance sector. 
- perception of economic policy (trust, psychological background, conditions, settings). It is based on the General subjective trust of citizens not only to insurance institutions, but also to the economy in common. This indicator reflects the attitude to the state as a guarantee of stability in the economy and a regulator of economic institutions.

Everything that was mentioned above are components (directions) of citizens' attitude to the insurance policy can be considered as a list of elements (indicators) included in the structure of the PIP. To confirm the importance of the role of Insurance Institute not only as a factor of economic full-fledged life of the citizen, but also as a factor of economic security of the individual, an integral psychological indicator that reduces financial anxiety and uncertainty of the individual, the scale of financial anxiety of the individual was introduced. Anxiety and hostility are interrelated [May, 2001]. Based on this statement, financial anxiety, together with the painful experience of helplessness in the situation of an insured event, loss of property, money, can cause negative and hostile reactions towards those who are responsible for the financial security of the individual. Combining indicators of anxiety, risk perception and attitude to economic policy into one tool, presumably, demonstrates how manifestations of financial anxiety affect the attitude of those who the citizen is ready to transfer on responsibility for their risks - the state, insurance companies or himself.

This method was developed to test the basic hypothesis, where citizens' perception of insurance is characterized by contradictory economic behaviour, which is manifested by insufficient psychological readiness of citizens to shift economic risks to insurance companies and confirm the first additional hypothesis that most Russian citizens are characterized by paternalistic attitudes in insurance behaviour and shifting responsibility for insurance events to state institutions. It was expected that in relation to the insurance policy citizens will be typologically different on "Paternalists" and "Supporter of market economy". The previous stages of the study of citizens' perception of insurance policy confirmed these hypotheses, but at this stage it was supposed to combine the significant psychological characteristics obtained in the previous stages of the study into a single tool and conduct a survey on a larger sample of respondents.

\section{Results and Discussion}

Factor analysis of the data was used to validate the proposed blocks. When processing the data, 10 factors were obtained, whose eigenvalue is greater than one. We have identified the 5 most interpretable factors, including the opinion on the approval 21 of 33 (Tab.2).

Table 2: Factor analysis of the data of the relation to insurance policy (PIP Inventory) N=304

\begin{tabular}{|c|c|}
\hline Statement & Factor load \\
\hline Financial anxiety factor $(1)$ & \\
\hline I often experience anxiety about the loss (deterioration) of my property & 675 \\
\hline I am constantly worried about my financial future & ,705 \\
\hline Lack of money is a common cause of my irritation & ,716 \\
\hline I sometimes think that with my car (apartment) should happen something terrible & ,721 \\
\hline I'm usually experience trouble and it is hard to forget them quickly &, 735 \\
\hline
\end{tabular}


Factor of attitude to economic policy (2)

I believe that the government and politicians are to blame for the economic problems of our country

I believe that improving the quality of life of citizens can be achieved primarily by competent economic laws

As a consumer, I am satisfied with the economic situation in the country

Factor rational attitudes and market behaviour (3)

I try to be aware of changes in the insurance programs, rates, terms and conditions of insurance, which is implementing the state policy

I generally trust insurance institutions and how the state regulates the insurance and investment market

I prefer to insure only in non-state insurance companies

I believe that insurance reduces (may reduce) financial worries about my property

I am well aware of the principles of taxation and the amount of taxes

The factor of the expediency of insurance (4)

I'd rather pay the insurance money than trust fate

I plan or already have life insurance

I only buy mandatory insurance programs (e.g. OSAGO)

I prefer to live for today and see no point in insurance

Risk perception factor (5)

I believe that the richer the citizen, the higher should be his tax liability

I believe that the risks associated with natural disasters should be borne by the state

I only buy mandatory insurance programs (e.g. OSAGO)

I believe that everyone, regardless of their income level, should regularly make 
It follows from table 2 that the first factor, which we call the financial anxiety factor, describes $12 \%$ of the total variance, is the largest. This factor includes the reflection of the citizen's feelings related to the possible loss of property, anxiety for the financial future, irritation about the lack of money and long-term concentration on disturbing events. Gathered these variables in the factor better than others showed correlations with each other. Financial anxiety plays an important role in the structure of relations to insurance. Financial uncertainty, the inability to control their financial future makes citizens look for ways to transfer their financial risks to insurance institutions in modern Russia.

The second factor indicates the dissatisfaction of the citizen as a consumer in solving economic problems by politicians and the government of Russia (the second factor of attitude to economic policy describes $10.67 \%$ of the total variance). Probably, it is connected with personal experience of ideas about economic policy of respondents. Citizens fix claims to the authorities, talking about the need to improve the quality of life of citizens through the introduction of competent economic laws and believe that the government and politicians are to blame for the economic problems of the country.

The third factor indicates the existence of strategies of market behaviour of Russian citizens (the third factor of rational attitudes and market behaviour describes $6.91 \%$ of the total variance). According to market views of respondents:

- you should trust insurance institutions and how the state regulates the insurance and investment market;

- insurance can reduce financial worries about your property;

- it is necessary to be aware of the changing conditions of insurance, tariffs and rules;

- there are no concerns about the transfer of their insurance risks to non-state insurance companies.

This factor, which combines the basic concepts of "Supporter of market economy", indicates the presence of market and rational approaches in the insurance behaviour of citizens.

The next fourth factor of expediency of insurance (describes $5.97 \%$ of the total variance) characterizes the preferences of citizens in the insurance policy of the household. He combined in himself the views of citizens on the feasibility, the benefits and the benefits of insurance products: need to pay money for the insurance than to trust to fate; not to live for today and to trust the insurance institutions; to buy not only the mandatory programs, and voluntary and even to plan for life insurance.

The fifth factor explains $4.67 \%$ of the total variance and is called the risk perception factor. This factor combined the respondents ' opinions on the perception, assessment and transfer of risks and responsibility for insurance events and other economic problems. The factor included the features of the factor that most reflect the characteristics of paternalistic attitudes: citizens ' ideas about the transfer of financial responsibility in tax policy to rich people, the transfer of responsibility for natural disasters to the state and the projected transfer of responsibility to citizens for their financial future, where everyone, regardless of their income level, should regularly make savings for the future. Also, the factor included the adoption of the 
responsibility of the citizen for the insurance of mandatory risks, such as CTP. Thus, the structure of the attitude to insurance policy included 5 factors that describe $41.25 \%$ of the obtained variance and empirically proved the correctness in the choice of the structural foundations laid initially in the PIP Inventory. Factor analysis and identified with the help of it the structure of the respondents had sent the basis for the selection of the typology of the respondents: "financial anxiety", "prosecuting authorities", "supporter of market economy", "active policyholders" and "paternalist". Next, consider the significant differences between these types and other variables in the PIP Inventory.

Two tests were used to analyze significant differences in the data: Mann-Whitney if the variable had two values and Kruskal-Wallise pairwise if the variable took more than two values.

The analysis of the data showed that there are no significant differences between the choice of insurance products and the presence of financial anxiety of the individual and citizens who accuse the government of the implementation of economic policy. Significant differences were observed between the choice of the insurance product and those groups that combined the features of the market behaviour factor ("Supporter of market economy"), the expediency of insurance ("Active policyholders") and the perception of risk ("Paternalists"). As can be seen from Table 3 among the "Supporter of market economy" using rational strategies in economic behaviour, there were more those who prefer to buy insurance policies OSAGO, KASCO, real estate insurance. "Active insurers" - buy expensive voluntary insurance programs (real estate insurance, hull insurance, VMI, life insurance). "Paternalists" are much less likely to participate in the active consumption of insurance products.

Table 3: Significant differences between groups using insurance products (U-Mann-Whitney criterion, $N$ - criterion Kruskal-Wallise test) $N=304$

\begin{tabular}{|c|c|c|c|c|c|c|c|c|c|c|}
\hline & \multicolumn{3}{|c|}{$\begin{array}{l}\text { Mortgage } \\
\text { insurance }\end{array}$} & \multicolumn{2}{|l|}{ OSAGO } & \multicolumn{3}{|c|}{ Travel insurance } & \multicolumn{2}{|c|}{$\begin{array}{l}\text { Real estate } \\
\text { insurance }\end{array}$} \\
\hline & & $\sigma$ & \multirow{2}{*}{$\begin{array}{l}\mathrm{M} \\
, 065^{*}\end{array}$} & \multirow{2}{*}{$\begin{array}{l}\sigma \\
, 069\end{array}$} & \multirow{2}{*}{$\begin{array}{l}\mathrm{M} \\
, 036\end{array}$} & \multirow{2}{*}{\multicolumn{2}{|c|}{$\begin{array}{l}\sigma \\
, 080\end{array}$}} & \multirow{2}{*}{$\begin{array}{l}\mathrm{M} \\
, 343 * * *\end{array}$} & \multirow{2}{*}{$\begin{array}{l}\sigma \\
, 107\end{array}$} \\
\hline $\begin{array}{l}\text { "Supporter of } \\
\text { market economy" }\end{array}$ &, 075 & & ,133 & & & & & & & \\
\hline $\begin{array}{l}\text { "Active } \\
\text { policyholders" }\end{array}$ & \multicolumn{2}{|l|}{, 150} &, 119 &, 044 &, 072 &, 051 & \multicolumn{2}{|c|}{,083 } &, $322 * * *$ & ,101 \\
\hline "Paternalists" & \multicolumn{2}{|l|}{,- 214} & ,123 &,- 007 & ,070 &, 056 & \multicolumn{2}{|c|}{,077 } &,$- 232 *$ & , 106 \\
\hline & \multicolumn{2}{|c|}{ KASCO } & \multicolumn{2}{|l|}{ VHI } & \multicolumn{2}{|c|}{$\begin{array}{l}\text { Accident } \\
\text { insurance }\end{array}$} & $\begin{array}{l}\text { Life } \\
\text { insurar }\end{array}$ & & \multicolumn{2}{|c|}{$\begin{array}{l}\text { Did not apply } \\
\text { to insurance } \\
\text { companies }\end{array}$} \\
\hline & $\mathrm{M}$ & $\sigma$ & \multirow{2}{*}{$\begin{array}{l}\mathrm{M} \\
, 142\end{array}$} & \multirow{2}{*}{$\begin{array}{l}\sigma \\
, 105\end{array}$} & \multirow{2}{*}{$\begin{array}{l}M \\
, 267\end{array}$} & \multirow{2}{*}{$\begin{array}{l}\sigma \\
, 432\end{array}$} & \multirow{2}{*}{$\begin{array}{l}\mathrm{M} \\
, 199\end{array}$} & \multirow{2}{*}{$\begin{array}{l}\sigma \\
, 120\end{array}$} & $\mathrm{M}$ & \multirow{2}{*}{$\begin{array}{l}\sigma \\
, 204\end{array}$} \\
\hline $\begin{array}{l}\text { "Supporter of } \\
\text { market } \\
\text { economy" }\end{array}$ & $\begin{array}{l}155^{*} \\
*\end{array}$ &, 082 & & & & & & & ,492 & \\
\hline $\begin{array}{l}\text { "Active } \\
\text { policyholders" }\end{array}$ & $\begin{array}{l}265 * \\
* *\end{array}$ &, 081 & $\begin{array}{l}, 337 * * \\
*\end{array}$ &, 104 &, 569 &, 261 & $\begin{array}{l}, 371 * \\
* *\end{array}$ &, 105 &,- 201 & ,215 \\
\hline "Paternalists" &,$- 153^{*}$ &, 083 &, $193^{*}$ &, 107 &,- 448 & ,276 &,- 044 & ,132 &, 180 & ,324 \\
\hline
\end{tabular}


Note: $p \leq 0,01-* ; p($ om 0,1 до 0,001) - **; $p<0,001-* * *$

Significant differences were found in 5 risk perception factors ("Paternalists") between those who work for state-owned enterprises and those working in the commercial sphere (Tab. 4). Among the "paternalists" are more those who work in the public sector and less those who work in the commercial sector.

Table 4: Significant differences between groups with different employment status (by Kruskal-Wallise $h$ - criterion) $N=304$

\begin{tabular}{lllllll}
\hline & Students & & \multicolumn{2}{c}{ Work in state enterprise } & \multicolumn{2}{c}{ Work in commercial sphere } \\
\cline { 2 - 7 } & $\mathrm{M}$ & $\sigma$ & $\mathrm{M}$ & $\sigma$ & $\mathrm{M}$ & $\sigma$ \\
"Paternalists" &,- 178 &, 142 &, 421 &, 121 &,- 165 &, 078 \\
\hline
\end{tabular}

There were significant differences in the 3 factors of market behaviour ("Supporter of market economy") and the assessment of subjective income (Tab 5). Those citizens who assess their income as low, rarely use market strategies in behaviour, they are not characterized by rational attitudes. There are more middle-income citizens who adopt market economic policies.

Table 5: Significant differences between groups with different estimates of subjective income (by Kruskal-Wallise $h$ - criterion) $N=304$

\begin{tabular}{llllllllllll}
\hline & \multicolumn{3}{l}{ Very low } & low & \multicolumn{3}{c}{ middle } & \multicolumn{2}{c}{ high } & \multicolumn{3}{c}{ Very high } \\
\cline { 2 - 12 } & $\mathrm{M}$ & $\sigma$ & $\mathrm{M}$ & $\sigma$ & $\mathrm{M}$ & $\sigma$ & $\mathrm{M}$ & $\sigma$ & $\mathrm{M}$ & $\sigma$ \\
$\begin{array}{l}\text { Supporter of market } \\
\text { economy" }\end{array}$ & - &, 157 &,- 437 &, 137 &, 125 &, 069 &,- 063 &, 209 & 1,362 &, 088 \\
\hline
\end{tabular}

The following distribution (Tab.6) found differences in financial anxiety ("Financial anxiety") between the poorest (group 1) and the wealthier groups, starting with those "who can buy, for example, basic household appliances (groups 3, 4 and 5).

Those experiencing financial anxiety and uncertainty are more among those who are experiencing financial difficulties and whose families have enough money only for food (group 1). Respondents from families with average incomes and above (groups 3, 4, 5) showed less financial anxiety and concern for their future.

There were significant differences in the attitude to economic policy ("Accusing the authorities") in relation to the assessment of the socio-economic status of the family. Citizens whose families are middle-income and above-average (group 3 and 4) are more likely to blame the government for the economic problems of the country and are dissatisfied with the consumer situation in the country.

Table 6: Significant differences between groups with different assessments of the socio-economic status of the family (by Kruskal-Wallise $h$ - criterion) $N=304$

\begin{tabular}{|c|c|c|c|c|}
\hline $\begin{array}{l}\text { Enough for } \\
\text { food, but it is } \\
\text { hard to buy } \\
\text { clothes } \\
\text { (1 group) }\end{array}$ & $\begin{array}{l}\text { Enough for } \\
\text { food and } \\
\text { clothes, but buy } \\
\text { in gfridge or } \\
\text { TV is difficult } \\
\text { ( } 2 \text { group) }\end{array}$ & $\begin{array}{l}\text { Able to buy } \\
\text { appliances, but } \\
\text { should get loan } \\
\text { to buy a car } \\
\text { ( } 3 \text { group) }\end{array}$ & $\begin{array}{l}\text { Enough money } \\
\text { but not for } \\
\text { apartment or } \\
\text { house purchase } \\
\text { ( } 4 \text { group) }\end{array}$ & $\begin{array}{l}\text { No financial } \\
\text { difficulties, able } \\
\text { to buy an } \\
\text { apartment or } \\
\text { house if } \\
\text { necessary }\end{array}$ \\
\hline
\end{tabular}




\begin{tabular}{lllllllllll} 
& $\mathrm{M}$ & $\sigma$ & $\mathrm{M}$ & $\sigma$ & $\mathrm{M}$ & $\sigma$ & $\mathrm{M}$ & $\sigma$ & $\mathrm{M}$ & $\sigma$ \\
$\begin{array}{l}\text { "Financial } \\
\text { anxious" }\end{array}$ &, 92 &, 243 &, 153 &, 174 &,- 013 &, 078 &,- 335 &, 119 &,- 622 &, 292 \\
$\begin{array}{l}\text { Blaming } \\
\text { authorities } \\
\text { " }\end{array}$ & -13 &, 247 &, 163 &, 175 &, 184 &, 080 &,- 412 &, 147 &,- 033 &, 469 \\
\hline
\end{tabular}

Influence of typological features of personality on the choice of compulsory or voluntary insurance programs In order to predict the influence of typological features on the choice of compulsory and voluntary insurance programs, an analysis was carried out using logistic regression, a method of constructing a linear classifier that allows to estimate the probability of belonging of objects to classes where the dependent variable took values 0 if the Respondent did not use optional insurance programs, and 1 if used. The calculation removed the scores of 20 respondents who had no insurance experience at all.

The compulsory programs included, conditionally, insurance programs, where the policyholder is forced to purchase an insurance policy at the request of banks or other structures: mortgage insurance (the policyholder is forced to purchase a mortgage insurance policy at the request of the Bank when obtaining a loan for an apartment or house), travel insurance for travelling abroad (the policyholder is forced to present it when obtaining a visa) and mandatory insurance program. All other programs (KASCO, real estate, life, accident, VHI) are included in the block of voluntary types of insurance, which are purchased at the request of the insured.

As a result of this work, the following final model was formulated (Tab.7).

Table 7: Influence of typological features of personality on the choice of compulsory or voluntary insurance programs

\begin{tabular}{lll}
\hline & Coefficient & p-value \\
\hline Constant & 1,44293 & $* * *$ \\
"Financial anxiety" &,- 08752 & \\
"Blaming authorities" &, 20463 & $* * *$ \\
"Supporter of market economy" &, 60533 & $* * *$ \\
"Active policyholders" &, 94361 & \\
"Patrernalistic" &,- 21688 & \\
Pseudo R-squared &, 26 & \\
\hline
\end{tabular}


The results of the regression analysis showed, that it is more likely that respondents included in the number of "relevant insurers" and "supporter of market economy" prefer the program of voluntary insurance. Thus, the possibility of a positive attitude of citizens to the insurance policy will be higher mainly among citizens who has already had experience with the insurance sector and citizens working in the commercial sector of the economy, using rational and market strategies in their economic behaviour.

To sum up the main results of the analysis of the attitude of citizens in insurance policy, we can make the following conclusions.

Nowadays citizens relation to insurance policy are divided:

- paternalistic citizens- those who often work in the public sector, do not trust insurance institutions, considering it impractical to transfer their property and nonproperty risks on the shoulders of business, insurance companies and other agents of the insurance market. They believe that all insurance contingencies should be the responsibility of the state and prefer to limit consumption by buying only compulsory insurance programs, such as OSAGO.

- the next category of citizens- those who work mainly in commercial sector, with middle income. They approve market policy of the state and increase the consumption of insurance products, including voluntary types of insurance. Their main strategies in making insurance-rationality in making decisions.

Most financially anxious citizens were those who have low subjective income and not participating in insurance activities. Those citizens who assess their income as low, rarely use market strategies in behaviour, they are not characterized by rational attitudes.

Among the citizens who accuse the government and politicians, there are more those who are dissatisfied with economic policy as a consumer. And more often it is citizens with average and above average income. But these citizens are less likely to experience financial anxiety for their future.

There is a category of citizens for whom insurance today is the main strategy for the preservation of all unforeseen situations. They acquire not only compulsory insurance programs, but also voluntary ones.

\section{Conclusions}

Thus, insurance trust is a necessary component of the investment behaviour of consumers. Citizen needs not only knowledge, but also faith in making serious longterm decisions to shift the risk to the insurance market agents.

It is necessary to stimulate the increase of financial literacy of citizens with materialistic attitudes, to increase trust to Insurance Institute and to develop rational qualities of the citizens' economic behaviour.

\section{Acknowledgments}

The study took into account the recommendations of the Department of social and economic psychology of the University of Gottingen (Dr. Katharina Gangl, GeorgAugust-University Gottingen, Georg-Elias-Müller-Institute of Psychology, Department of Economic and Social Psychology), the Federal network 
methodological canter of the Moscow State University within the project of the Ministry of Finance of the Russian Federation and the world Bank "Promotion of financial literacy and development of financial education in the Russian Federation". Parts of scientific research were performed at the Scientific Park of St. Petersburg State University "Canter for Sociological and Internet Research" (Dr. V.N Minina, S. M. Snopova, D. Yudina) and The American psychological Association in the analysis of journal article about standards for qualitative primary and mixed research methods.

\section{References}

[1] Definition of "at random". (2018, October 13). Available: https://dic.academic.ru/dic.nsf/efremova/

[2] Programs and projects to improve financial literacy. (2018, October 14). Available: http://ur-consul.ru/Bibli/Povyshyeniye-finansovoyi-gramotnostinasyelyeniya-myezhdunarodnyyi-opyt-i-rossiyiskaya-praktika.html.

[3] Gupta, B. (2011). Financial Services Review. The financial planning and training agenda in Australia. Vol.20, no.1, pp. 61-74

[4] Organisation of Economic Co-operation and Development (OECD) (2016), G20/ OECD/IFRS "Conception of basic skills and knowledge on financial literacy for adults". Available: https://www.oecd.org/finance/financial-education/

[5] Ryff C.D \& Singler B.H. (2008) Know thyself and become what you are: A eudemonic approach to psychological well-being. Journal of Happiness Studies. Vol.9 2008. pp. 13-39

[6] Overton R. (2008) Theories of the financial planning profession. Journal of Personal Finance. Vol. 7, no.1 pp. 13-41.

[7] Deyneka O.S. (2015). Experience of empirical studies of political and economic consciousness. Bulletin of St. Petersburg University. Episode 16. No. 3. pp. 1326.

[8] Medyanik O. (2017) The factor of economic security of person in regulation of insurance and investment policy. International Psychological Applications Conference and Trends (InPACT 2017). Book of abstracts. Ed. by Clara Pracana and Michael Wang. Lisbon: W.I.A.R.S. P.29.

[9] Medyanik O. (2018) Longidinal study of the Russian citizen's attitude toward the institutions of insurance and investment. International Psychological Applications Conference and Trends (InPACT 2018). Book of abstracts. Ed. by Clara Pracana and Michael Wang. Lisbon: W.I.A.R.S. P.32.

[10] Rollo M. The Problem of anxiety. Ed. from English. A. G. Gladkova.Moscow: Izd-vo Eksmo-Press, 2001. P.432. (Series "Psychology. Twentieth century") 